\title{
EL INTERÉS SUPERIOR DEL NIÑO COMO CONCEPTO JURÍDICO INDETERMINADO Y SU CONCRECIÓN EN LA JURISPRUDENCIA NACIONAL
}

\author{
THE BEST INTERESTS' PRINCIPLE AS A AS AN INDETERMINATE \\ LEGAL CONCEPT AND ITS CONCRETION IN THE NATIONAL \\ JURISPRUDENCE
}

\author{
Silvia Jenifer Herencia Espinoza ${ }^{1}$ \\ Universidad Femenina del Sagrado Corazón \\ Lima, Perú \\ https://orcid.org/0000-0001-5443-5286 \\ silviaherenciae@unife.edu.pe
}

\section{Resumen}

La aplicación del principio del interés superior del niño, como un enunciado de obligatoria aplicación, se remonta a la Convención del Niño; instrumento internacional que, por su carácter abstracto, ha requerido que en nuestro país se emita una norma que determine los parámetros de aplicación, con la finalidad que se justifique la adopción de medidas que resulten lo más satisfactorias para el desarrollo integral del menor. Si bien este principio viene siendo incorporado en las decisiones jurisdiccionales, la interpretación a que se está arribando resulta ser todavía muy amplia, sin efectuar una ponderación adecuada entre las posibles soluciones, a fin de establecer cuál de ellas resulta ser la más conveniente para el menor.

Palabras clave: Desarrollo integral, menor, Corte Suprema, principio del interés superior del niño, concepto jurídico indeterminado.

\section{Abstract}

The application of the principle of the best interests of the child, as a statement of mandatory application, dates to the Children's Convention; Due to its abstract nature, it has required that in our country a regulation be issued that determines the application parameters, in order to justify the adoption of measures that are the most satisfactory for the integral development of the minor. Although this principle has been incorporated in the jurisdictional decisions, the interpretation to which it is arriving turns out to be still very broad, without making an adequate weighting

1 Silvia Herencia, Abogada y Magíster en Derecho de Empresa, Pontificia Universidad Católica del Perú, Lima, Perú. Actualmente, se desempeña como Jueza Titular de la Corte Superior de Justicia de Lima Este y Docente Universitaria en la Universidad Femenina del Sagrado Corazón y en la Pontificia Universidad Católica del Perú, Lima, Perú. 
between the possible solutions, in order to establish which of them turns out to be the most convenient for the minor.

Keywords: Comprehensive development, child, Supreme Court, best interests of the child, indeterminate legal concept.

\section{INTRODUCCIÓN}

La Convención sobre los Derechos del Niño (1989) es la primera norma de carácter internacional que regula, de manera obligatoria, los derechos asignados a los niños y las niñas. Dicha Convención recogió lo dispuesto en la Declaración de los Derechos del Niño de 1959, en especial el principio del interés superior del menor, el cual delimita la actuación del Estado y de los órganos jurisdiccionales, precisando que al resolver un conflicto en el que se vea involucrado un niño o niña se deben priorizar y establecer todas las medidas que le permitan asegurar la adecuada protección y cuidado, permitiendo así su desarrollo integral, en ese sentido, indica que:

En todas las medidas concernientes a los niños que tomen las instituciones públicas o privadas de bienestar social, los tribunales, las autoridades administrativas o los órganos legislativos, una consideración primordial a que se atenderá será el interés superior del niño. (Convención sobre los Derechos del Niño, 1989, art. 3).

De igual forma, la Convención reconoce el derecho que tiene el niño de vivir con sus padres, salvo que la separación sea necesaria por el interés superior del niño; asimismo, "señala que es responsabilidad de los padres la crianza y desarrollo del niño", siendo la preocupación fundamental su interés superior (Convención sobre los Derechos del Niño, 1989, art. 9 y 18).

De la lectura de los artículos antes indicados, podemos evidenciar la importancia de su implementación y desarrollo en las decisiones que afecten o involucren a menores; sin embargo, no encontramos la definición, el contenido y alcances de este principio, que nos permitan determinar cuáles son las medidas idóneas en contraposición con otras que pudieran adoptarse. Esa generalidad en su previsión determina que éste sea considerado como un principio de carácter abstracto o indeterminado.

Es por ello que, Ratvellat lo conceptualiza como un concepto flexible, dinámico que permite que se vaya adecuado o perfilando caso a caso (2013, p. 92), mientras que, Cárdenas Miranda lo identifica como un concepto jurídico 
indeterminado de aplicación internacional, pero cuya definición no resulta fácil de obtener (2011, p. 6).

\section{Un concepto jurídico determinado ha sido establecido como}

"un término jurídico que, debido a la ductibilidad del derecho, está presente en toda estructura y rama de lo jurídico, y puede adoptar forma de valor o de principio jurídico, de derecho subjetivo, de deber $\mathrm{u}$ obligación jurídica, o simplemente estar incluido como una palabra más - sin definir de una manera concreta- en la norma, sea ésta de carácter nacional o internacional y, cuya presencia en el Derecho, tiene por causa o las características propias de la vaguedad y ambigüedad que presenta el lenguaje común, a las que no es ajeno el lenguaje jurídico, o la intención premeditada del legislador de redactar de esta manera imprecisa la norma a modo de técnica de normación" (Pacheco, 2013, pág. 25)

En cuanto a la estructura, un concepto jurídico indeterminado contiene un supuesto hipotético ambiguo o abstracto y, ello es así porque resulta imposible anticipar todas las posibles situaciones que pueden ser contemplados en él. Es por ello, que Cassagne refiere que para dar contenido a un concepto jurídico indeterminado debemos reconocer su configuración, es así que, se establece la existencia de: "a) un núcleo fijo o zona de certeza positiva, integrado por elementos precisos; b) un 'halo conceptual' o zona de incertidumbre, de menor precisión, es decir, donde reina cierta ambigüedad; y, por último, e) una zona de certeza negativa, que comprende situaciones claramente excluidas del supuesto contemplado en la norma (2009, pág. 88)".

Tomando en consideración que la composición del concepto jurídico indeterminado contiene una zona de incertidumbre, corresponde realizar a los operadores jurídicos una labor de interpretación a fin de establecer una solución justa, eliminando la incertidumbre y estableciendo cuál de los diversos significados resulta el más adecuado para resolver el caso concreto.

Esa misma estructura se evidencia cuando hacemos referencia al concepto "interés superior del niño", el cual, dada la amplitud de medidas que se pueden adoptar para resolver los conflictos en los que se vean involucrados los menores. En atención a lo expuesto, la pregunta que surge es: ¿cómo se da contenido al supuesto de hecho normativo, evitando la discrecionalidad $\mathrm{y}$, sobre todo, eligiendo, en los conflictos parentales y conflictos en torno a la niñez o adolescencia familiares, las disposiciones que son más favorables para los menores? 
Respondiendo a dicha interrogante Belloso señala que

"La justicia debe estar presente en estos casos, máxime cuando en la mayor parte de las ocasiones se utiliza la fórmula interés superior del menor, de esencia claramente finalista. Esto significa que se debe de dejar a un lado lo que a cualquiera de las otras partes implicadas en el caso les pudiera resultar más conveniente para hacer primar el interés del menor por encima de cualquier otra consideración" (Belloso, 2017, pág. 17)

En nuestro país, gracias a la promulgación de la "Ley que establece parámetros y garantías procesales para la consideración primordial del interés superior del niño" (Ley N. ㅇ 30466, 2016), así como, su Reglamento (Decreto Supremo N.- 002-2018-MIMP), contamos con un instrumento normativo que permite analizar esta estructura a la que hace referencia Cassagne, toda vez que, la primera de ellas reconoce "al Interés Superior del Niño como un derecho, un principio y una norma de procedimiento que les confiere a los niños, niñas o adolescentes un derecho prioritario frente a cualquier medida a adoptar que los involucre"(Ley № 30466, 2016, art. 2), reafirmando el carácter universal del principio, así como, el reconocimiento de los niños como titulares de derechos.

Por su parte, el Reglamento resalta los factores que se deben considerar para la evaluación de circunstancias concretas de los niños, tales como: las características personales, así como la necesidad de priorizar los derechos del menor cuando entren en conflicto con otros derechos. Igualmente, se establece qué factores se deben tomar en consideración para la aplicación de este principio, señalando, la necesidad de escuchar su opinión, preservar su identidad y la del entorno familiar, entre otros; constituyendo la parte medular de esta norma, la cual estipula que:

Todas las decisiones tomadas por las autoridades competentes de las entidades públicas de los tres niveles de gobierno deben estar motivadas, justificadas y explicadas. En la motivación se deben señalar explícitamente todas las circunstancias de hecho referentes a la niña, niño o adolescente, los elementos que se han considerado pertinentes para la evaluación de su interés superior, el contenido de los elementos en ese caso concreto y la manera en que se han ponderado para determinar el interés superior del niño.

Si la decisión difiere de la opinión de la niña, niño o adolescente, se debe exponer con claridad la razón por la que se ha tomado... (Decreto Supremo № 002-2018-MIMP, 2018, art. 12.6). 
Lo expuesto en la norma nos permite corroborar que el principio del Interés Superior del Niño es un concepto abstracto, indeterminado cuyo contenido debe ser establecido vía interpretativa, labor que exige una adecuada motivación en la que pueda establecerse cuáles son los derechos concurrentes y, de manera especial, que permita constatar la ponderación efectuada, con la finalidad de justificar por qué la medida adoptada resulta ser la que permita al niño, niña o adolescente ese desarrollo integral al que tiene derecho.

Esta labor interpretativa se realizará en cada caso a resolver, a fin de ir generando pautas que permitan identificar qué medidas resultan más favorables, sin olvidar que, dicha labor se debe cumplir, en un marco de predictibilidad, pues la seguridad jurídica es uno de los principios generales del derecho y, teniendo presente que serán las máximas instancias, como la Corte Suprema, quienes tendrán que fijar los criterios que servirán de fundamento para la solución de casos similares, evitando respuestas jurídicas contradictorias; $y$, por sobre todo, considerando que a los niños y adolescentes se les debe ofrecer la posibilidad de expresar sus sentimientos y opiniones con la finalidad que sean tomados en cuenta por el juzgador en función de su madurez, edad y capacidad de discernimiento; en tal sentido, de tomarse una decisión contraria a dicha opinión, deberá justificarse adecuadamente el motivo de la discrepancia, ello, por su cualidad de sujetos de derechos.

Por tal motivo, analizaremos, cómo en el ámbito del Poder Judicial se viene interpretando dicho principio y, si en cada actuación judicial, se cumple con su aplicación en los términos establecidos en la Convención sobre los Derechos del Niño, la Ley № 30466 y el Decreto Supremo № 0022018-MIMP.

\section{EL PRINCIPIO DEL INTERÉS SUPERIOR DEL NIÑO EN LA JURISPRUDENCIA DEL PODER JUDICIAL}

Para realizar esta evaluación se han tomado cuatro resoluciones emitidas por la Corte Suprema de Justicia del Perú, que si bien es una muestra pequeña se justifica en que no muchos casos, con la nueva normatividad, han llegado a ser resueltos por la máxima instancia del Poder Judicial. En cada caso, fijaremos los criterios interpretativos aplicados al resolver los procesos, con la finalidad de establecer si la interpretación realizada evidencia la adopción de las medidas más favorables y que permitan el desarrollo integral de los niños, niñas o adolescentes involucrados

Como se podrá apreciar más adelante, estas sentencias reflejan conflictos en el ámbito familiar, tales como: régimen de visitas, la restitución del menor 
y el derecho a la identidad; las cuales, en su emisión han hecho referencia al principio del interés superior del niño; sin embargo, la pregunta que cabe es si en el desarrollo de las sentencias se ha determinado qué significa, en el caso concreto, este principio y, si se ha efectuado la ponderación que permita identificar que la medida adoptada resulta más beneficiosa para el niño.

\section{Caso 1}

\begin{tabular}{|l|l|}
\hline Referencia & $\begin{array}{l}\text { Corte Suprema de Justicia de la República Sala Civil Perma- } \\
\text { nente Casación No 516-2019 ICA } \\
\text { Reconocimiento de tenencia y custodia de menor. }\end{array}$ \\
\hline Interrogante & $\begin{array}{l}\text { iSe delimitó el concepto del interés superior del niño al estable- } \\
\text { cer el régimen de visitas con externamiento? }\end{array}$ \\
\hline $\begin{array}{l}\text { Katherine y Alfredo contrajeron matrimonio, producto de dicha } \\
\text { relación nace su hija; sin embargo, él hizo abandono del hogar } \\
\text { conyugal, incumplió la obligación alimentaria con su hija, por lo } \\
\text { que la madre tuvo que interponer una demanda de alimentos. } \\
\text { Posteriormente, la madre presenta una demanda de reconoci- } \\
\text { miento de tenencia y custodia a fin de cautelar el derecho de su } \\
\text { menor hija, indicando que el demandado viene maltratándola } \\
\text { y amenazando con quitársela y desaparecer con ella para que } \\
\text { nunca más la vuelva a encontrar, causándole mucha preocupa- } \\
\text { ción, alega además que a ella también la maltrataba físicamente. } \\
\text { El demandado es rebelde en este proceso. } \\
\text { del caso }\end{array}$ & $\begin{array}{l}\text { En el acto de audiencia, la menor manifestó su deseo de seguir } \\
\text { viviendo con su madre, pero a su vez hizo saber que le gustaría } \\
\text { que su padre la visite y la saque a pasear. } \\
\text { La sentencia de primera y segunda instancia amparan la de- } \\
\text { manda y confieren al padre un régimen de visitas con externa- } \\
\text { miento. } \\
\text { La demandante interpone recurso de casación alegando que: } \\
\text { El demandado incumple con las obligaciones alimentarias } \\
\text { de su menor hija, habiendo sido denunciado hasta en 4 } \\
\text { oportunidades por omisión a la asistencia familiar. } \\
\text { El demandado no tiene arraigo familiar en la provincia de } \\
\text { Chincha, también consigna diferentes domicilios durante } \\
\text { los procesos penales que se le sigue por omisión de asis- } \\
\text { tencia familiar, no teniendo un domicilio fijo y permanente, } \\
\text { por lo que pone en riesgo el cumplimiento de los mandatos } \\
\text { judiciales. }\end{array}$ \\
\hline
\end{tabular}




\begin{tabular}{|c|c|}
\hline $\begin{array}{l}\text { Fundamentos } \\
\text { de la Corte } \\
\text { Suprema }\end{array}$ & $\begin{array}{l}\text { La Corte Suprema indica que en segunda instancia la Sala Su- } \\
\text { perior ha efectuado una valoración superficial de las pruebas } \\
\text { respecto a la idoneidad de la conducta del padre de la menor } \\
\text { que permita sugerir que las visitas en favor de ésta última se } \\
\text { efectúen con externamiento, } \\
\text { Respecto al incumplimiento de pago de la obligación alimen- } \\
\text { taria, precisa que el artículo } 88 \text { del Código de los Niños y Ado- } \\
\text { lescentes - norma que dispone que el padre debe acreditar estar } \\
\text { al día en el pago de las obligaciones alimentarias para acceder } \\
\text { al derecho de visitas- debe interpretarse en concordancia con el } \\
\text { principio del interés superior del niño. } \\
\text { Concluye que durante el régimen de visitas sin externamiento, } \\
\text { la menor y sus progenitores deberán asistir a terapia psicológica } \\
\text { ante la psicóloga adscrita al Segundo Juzgado de Familia, por } \\
\text { un periodo de un año, cuyo profesional deberá emitir un infor- } \\
\text { me a dicho Juzgado. }\end{array}$ \\
\hline
\end{tabular}

Elaboración propia

En este primer caso, frente al pedido formulado por la madre de una niña para que se reconozca la tenencia de hecho que ejerce y por el temor que siente ante la posibilidad que el padre se la lleve, la primera y segunda instancia si bien amparan la demanda reconociendo que la tenencia sea ejercida por ella, también — sin haber sido pedido-conceden un régimen de visita con externamiento para el padre, amparando su decisión en la aplicación del principio del interés superior del niño. De lo expuesto por la resolución en análisis, no se advierte cuáles son los fundamentos para conceder el derecho de visitas con externamiento, cuando en el proceso nunca participó el padre.

Ello, permite advertir que una madre, cuyo propósito era proteger a su hija frente a la posibilidad que el padre la aleje del entorno materno y, pese a que no hay pedido alguno formulado por parte de él, deba transitar por tres instancias (Juzgado Especializado, Sala Superior y luego la Corte Suprema), para que se evalúe qué medidas resultan más favorables para la niña.

En este caso, es la Corte Suprema quien realiza la ponderación de las medidas a adoptar para la resolución del caso y, da respuesta al cuestionamiento que surge ¿Debe fijarse un régimen de visitas? y, de ser así ¿Bajo qué modalidad debe realizarse?, para ello, toma en consideración, lo siguiente: 
El padre no se encontraba al día en las pensiones alimentarias; sin embargo, comprueba que éste no puede ser un impedimento para el desarrollo del vínculo afectivo con el padre, siendo fundamental que las necesidades emocionales sean consideradas al resolver, pues tan importante es la provisión de alimentos como la relación afectiva, para ello, considera que la menor muestra afecto hacía su padre, y ha expresado su deseo de que éste la visite.

Frente a las posibles alternativas de solución, la Corte Suprema prioriza la salud emocional de la niña y concluye que, aun cuando el padre no haya cumplido con la obligación alimentaria en favor de la niña, la relación que debe existir entre padre e hija no se puede ver afectada, pues ello permite su desarrollo emocional; por ello, concluye que, el régimen de visitas debe ser amparado.

Respecto del modo en que este régimen debe ser ejecutado, considera que el demandado ha sido declarado rebelde, por lo que existe verdad relativa sobre los hechos expuestos, en particular lo relativo a la existencia de actos de violencia contra la mujer de la que habría sido víctima la demandante, quien ha obtenido medidas de protección a su favor, no pudiendo señalarse que dichos actos no incidirían en la relación padre hija; asimismo, que el demandado no ha pasado por ninguna evaluación psicológica, ni asistido a las terapias psicológicas ordenadas en la sentencia por el Juzgado que resolvió la denuncia por violencia; todo esto, permitiría tener un criterio respecto a la personalidad del demandado y prever la inexistencia de algún riesgo para la menor, quien a la fecha tiene siete años y, además, no ha acreditado un arraigo domiciliario.

Concluye que, por el momento, no resulta atendible que el régimen de visitas otorgado a favor del padre de la menor se realice con externamiento.

El análisis de los hechos y comportamiento del demandado permite a la Corte concluir que las visitas deban realizarse sin externamiento, pero con el acompañamiento psicológico, por el periodo de un año, luego del cual, se realizará el informe correspondiente.

Ahora, si bien en la sentencia de la Corte Suprema expresamente no se detalla la forma en que se llena de contenido este principio, pero, de la estructura del mismo, en los términos de Cassagne, se puede evidenciar en el desarrollo de la sentencia, de tal forma que, el núcleo fijo está constituido por las medidas a adoptar, las cuales deben permitir el desarrollo integral de la niña, la zona de incertidumbre, de menor precisión, es decir, donde reina cierta ambigüedad, 
resulta ser la más beneficiosa: en este caso, el reconocer el derecho de la niña

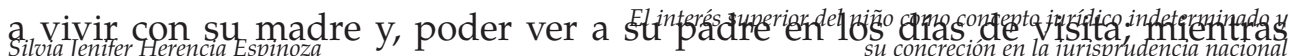
que, la zona de certeza negativa, estará determinada por la imposibilidad de poner en riesgo la salud emocional de la niña, lo que nos permite concluir que la sentencia emitida sí ha priorizado el interés superior del niño al emitir pronunciamiento, lo que no se verificó en las instancias inferiores.

\section{Caso 2}

\begin{tabular}{|c|c|}
\hline Referencia & $\begin{array}{l}\text { Corte Suprema de Justicia de la República, Sala Civil Permanente Ca- } \\
\text { sación N.․ 2728-2017 LIMA NORTE }\end{array}$ \\
\hline Interrogante & $\begin{array}{l}\text { ¿Se delimitó el concepto del interés superior del niño en el proceso de } \\
\text { restitución internacional de menor? }\end{array}$ \\
\hline $\begin{array}{l}\text { Planteamiento } \\
\text { del caso }\end{array}$ & $\begin{array}{l}\text { Thorbjorn y Andrea contrajeron matrimonio, producto de dicha rela- } \\
\text { ción nace su hija en Noruega. Luego de la separación de los padres, } \\
\text { ellos acuerdan que la niña viviría con la madre y, el padre la visitaría. } \\
\text { En abril de 2015, la madre viaja con la niña a Perú, permaneciendo } \\
\text { tres meses, pese a que el padre sólo autorizó dos semanas. En agosto } \\
\text { de 2015, la madre informa estar en Noruega; sin embargo, el padre } \\
\text { no podía visitar a la niña, por los cambios constantes de domicilio. El } \\
\text { padre solicita la plena guarda y custodia y que se prohíba la salida, lo } \\
\text { que le fue concedido. } \\
\text { En setiembre de 2015, el padre se entera que la niña con su madre se } \\
\text { encontraba en Perú, pese al impedimento de salida, por lo que, formu- } \\
\text { la la denuncia a las autoridades de su país. } \\
\text { El Ministerio de la Mujer y Poblaciones Vulnerables del Perú, en repre- } \\
\text { sentación de Thorbjorn interpone demanda de restitución internacio- } \\
\text { nal de menor. } \\
\text { La madre se apersona al proceso e indica que vino al Perú sin autori- } \\
\text { zación del cónyuge, afirmando que éste la maltrataba, así como que, } \\
\text { uno de los hijos del padre efectuó tocamientos indebidos a la menor } \\
\text { según la denuncia que interpuso. Respecto de ello, el demandante ha } \\
\text { presentado documentación en la que se acredita que la denuncia sobre } \\
\text { violencia familiar presentada por Andrea contra el hijo de Thorbjorn } \\
\text { fue sobreseída por las autoridades noruegas. } \\
\text { En Primera y Segunda instancia se resolvió amparar la deman- } \\
\text { da de restitución internacional de la niña; en consecuencia, se } \\
\text { ordena que se le restituya al país de Noruega, debiendo el padre } \\
\text { sufragar los gastos que ocasionan el regreso de la niña; quien } \\
\text { deberá arribar al domicilio que tenía al momento de la sustrac- } \\
\text { ción o al domicilio paterno; en el caso que la madre no pueda } \\
\text { acompañar a la niña de regreso a su país de origen. }\end{array}$ \\
\hline
\end{tabular}




\begin{tabular}{|c|c|}
\hline & $\begin{array}{l}\text { La demandante interpone recurso de casación alegando que: } \\
\text { - No se ha tomado en consideración que el padre ha admiti- } \\
\text { do que la menor vivía únicamente con la madre, y él sola- } \\
\text { mente la visitaba esporádicamente, por lo que, expresa ca- } \\
\text { recería de sustento la restitución de la menor y su entrega al } \\
\text { cuidado de terceras personas, alejándose de su progenitora. } \\
\text { - No se ha desarrollado ningún análisis del medio familiar } \\
\text { donde se desenvuelve el menor; máxime, si no ha existido } \\
\text { informe de asistencia social, ni del centro educativo donde } \\
\text { estudia la menor. } \\
\text { No se ha valorado el hecho de la violencia sexual sufrido } \\
\text { por la menor por parte del hermano paterno, por lo que } \\
\text { existe un grave riesgo de que la restitución del menor lo } \\
\text { exponga al peligro. }\end{array}$ \\
\hline $\begin{array}{l}\text { Fundamentos } \\
\text { de la Corte } \\
\text { Suprema }\end{array}$ & $\begin{array}{l}\text { La Sala Suprema indica que: } \\
\text { Respecto de la motivación que, la sentencia de vista se encuentra debi- } \\
\text { damente motivada, al haber valorado todos los medios probatorios ac- } \\
\text { tuados en autos y emitida dando respuesta a los agravios de apelación } \\
\text { interpuesto por la recurrente. } \\
\text { Respecto a la aplicación del interés superior del niño, indica que la de- } \\
\text { cisión judicial emitida debe contener un análisis adecuado del princi- } \\
\text { pio de interés superior del niño, en la medida también que éste resulta } \\
\text { ser el principio rector que impone al Estado no solo la obligación de } \\
\text { adoptar todas las medidas positivas que aseguren la rápida y eficaz } \\
\text { protección de los niños, sino que además constituye el factor de ins- } \\
\text { piración de las decisiones que sobre restitución internacional deban } \\
\text { adoptarse. } \\
\text { Para los casos de sustracción de menores el régimen jurídico interna- } \\
\text { cional aplicable es la Convención de la Haya sobre los Aspectos Civiles } \\
\text { de la Sustracción Internacional de Menores y la Convención Interna- } \\
\text { cional sobre los Derechos del Niño, el cual, contempla mecanismos de } \\
\text { excepción a efectos de determinar que el menor no retorne a su país } \\
\text { tales como: b) Que haya peligro físico o psíquico para el menor en caso } \\
\text { de retornarlo a su lugar de residencia. } \\
\text { Concluye que no existen motivos que determinen que el traslado, al } \\
\text { país de origen, ponga en riesgo la integridad física y mental, por lo } \\
\text { que, el traslado de la referida menor por parte de la demandada al Perú } \\
\text { configura un "Traslado Ilícito", a la luz de la Convención, pues la re- } \\
\text { sidencia habitual de la menor siempre fue en Noruega, su lugar natal, } \\
\text { hasta la edad de los cinco años en que fue traslada ilícitamente al Perú. }\end{array}$ \\
\hline
\end{tabular}

Elaboración propia 
En este caso, el Ministerio de la Mujer y Poblaciones Vulnerables interpone la demanda de restitución, en representación de un ciudadano noruego, por el traslado al Perú de su hija, sin su consentimiento. Ante ello, el Poder Judicial, en todas las instancias amparan la demanda y ordenan que la niña regrese a Noruega, debiendo arribar al domicilio paterno o al domicilio que tenía al momento de la sustracción; en el caso que la madre no pueda acompañar a la niña de regreso a su país de origen.

Conforme a lo resuelto, se presentan dos alternativas:

1. La niña regresa al domicilio de su padre, con quien no ha vivido desde los tres años y con su medio hermano, quien tiene una denuncia sobreseída por tocamientos indebidos o,

2. Regresa al domicilio que tuvo antes de la sustracción, el cual, conforme a lo señalado en la demanda, cambiaba constantemente, traslado que se realizaría aun cuando, la madre, con quien ha vivido siempre, no pueda acompañarla.

Surgen algunas interrogantes: ¿es esta la medida que permite el desarrollo integral de la niña?, ¿cuál es la opinión de la niña respecto del retorno a su país de origen?, ¿cuál es la conclusión del informe emitido por el equipo multidisciplinario respecto al desarrollo de la menor?, ¿por qué, en este caso, las instancias del Poder Judicial, a diferencia del caso anterior (en el que se precisa que los actos de violencia denunciados por la madre en su contra podrían incidir en la relación padre-hija), consideran que los conflictos que pudieran suscitarse entre la pareja no deben perjudicar las relaciones paterno filiales?

Frente a este último hecho, podemos apreciar que la Sala Civil Permanente de la Corte Suprema adopta pronunciamientos disímiles, situación que afecta la predictibilidad de las resoluciones judiciales.

De otro lado, se puede evidenciar que la Corte delimita su accionar, a señalar cuáles son los argumentos que le llevan a establecer que hubo un traslado ilegítimo y ordenar la restitución de la niña, sin precisar si estos argumentos llevan a adoptar una decisión que reconozca a la niña como sujeto de derecho y que las medidas adoptadas le son realmente convenientes.

En ese sentido, indica que la menor estuvo al cuidado de ambos padres durante sus cinco primeros años en el país de Noruega. Si bien se encontraban separados, y por dicha razón fijaron un régimen de visitas, durante el tiempo que vivió en el país de Noruega desde su nacimiento hasta 
antes de ser traslada al Perú, ella cuenta con una permanencia de menos de dos años en el Perú, habiendo tenido solo interrelación con la demandada; $y$, estando determinada su residencia habitual antes de su traslado, concluye que aquélla no se encuentra integrada al ambiente en que actualmente vive, siendo que su retorno es necesario.

Respecto del hecho de la violencia sexual sufrida por la menor por parte del hermano paterno el hecho imputado por la demandada no se ha probado, al haberse sobreseído la denuncia.

Puntualiza que:

(i) La menor es de nacionalidad noruega;

(ii) Sus padres ejercen Patria Potestad Compartida;

(iii) El padre tenía un régimen de visitas;

(iv) La madre y la menor llegaron a Perú en el año 2015;

(v) No se ha acreditado que la demandada haya tenido consentimiento expreso del padre de la menor para traer a su hija de su país natal Noruega, ni que el acuerdo sobre régimen de visitas haya sido modificado o dejado sin efecto;

(vi) La denuncia que la madre hizo sobre presuntos tocamientos indebidos en contra el hijo del demandado fue archivada;

(vii) Los conflictos que pudieran suscitarse entre pareja no deben perjudicar las relaciones paternofiliales.

Sin embargo, consideramos que con la finalidad de establecer cuál es esa medida que resulte más favorable para la niña, podemos confrontar los mismos, de la siguiente manera: por un lado, tenemos a una niña de 8 años, de los cuales 5 de ellos ha vivido sólo con la madre; que lleva viviendo en el Perú 3 años, y que se encuentra en etapa escolar, lo que evidencia que, ha generado vínculos amicales con sus compañeros de clases; que tiene un medio hermano denunciado por tocamientos indebidos en su contra; $y$, que su madre ha denunciado hechos de violencia en su contra por parte del padre, lo que, de alguna manera, determinan el entorno parental. De ampararse el pedido de restitución, la niña, quien sólo vivió tres años con el padre, debe retornar al entorno paterno o al último domicilio que tuvo en Noruega, sin su madre.

Cabe señalar que en este proceso no se ha escuchado la opinión de la niña ni se ha precisado cómo se siente respecto del retorno a Noruega o la posibilidad de permanecer el Perú, o con la posibilidad de vivir con su padre y medio hermano y dejar de vivir con su madre; no obstante ser sujeto de derechos. 
Por otro lado, se debe considerar que la niña tiene derecho a gozar de las visitas de su padre y mantener la relación paterno filial, la cual se dificulta al permanecer ella en el Perú; adicionalmente, ella fue alejada de su país natal y ha permanecido en Perú, pese a no contar con el consentimiento de su padre.

Hechos que, conforme a los parámetros establecidos en la Ley del interés superior del niño y desarrollados en el Reglamento, debían ser contrapuestos, de tal forma que, se permita determinar las medidas más favorables para el bienestar de la niña, lo que no ha sucedido.

Precisar el contenido del principio del interés superior del niño, en el caso concreto, supone, como se ha mencionado anteriormente: el establecimiento del núcleo fijo, las medidas que permitan el desarrollo integral de una niña nacida en Noruega y cuyo padre solicita retorne a su país natal. La zona de incertidumbre: establecer si la niña debe permanecer o retornar a su país; $y$, la zona de certeza negativa: la solución al caso debe tomar en consideración que la situación emocional no debe empeorar.

Por lo tanto, podemos concluir que, en el presente caso, no se ha determinado el contenido de este concepto indeterminado ni se ha establecido que la medida adoptada es la más favorable para la niña.

\section{Caso 3}

\begin{tabular}{|l|l|}
\hline Referencia & $\begin{array}{l}\text { Corte Suprema de Justicia de la República Sala Civil Permanente } \\
\text { Casación No 5646-2017 Cusco } \\
\text { Impugnación de Paternidad }\end{array}$ \\
\hline Interrogante & $\begin{array}{l}\text { ¿Se delimitó el concepto del interés superior del niño al resolver un } \\
\text { conflicto en el que se debe determinar la identidad? }\end{array}$ \\
\hline Planteamiento del \\
caso & $\begin{array}{l}\text { David y Marcela contrajeron matrimonio. Durante la vigencia del } \\
\text { matrimonio nacen dos niños, uno de ellos nació en el año 2007, } \\
\text { quien por disposición del artículo 361 del Código Civil, goza de } \\
\text { la presunción de paternidad matrimonial, siendo reconocida por } \\
\text { David como su padre. }\end{array}$ \\
$\begin{array}{l}\text { Posteriormente, ante las dudas de su paternidad, se practicó una } \\
\text { prueba de ADN, comprobando no ser el padre biológico de la niña. }\end{array}$ \\
$\begin{array}{l}\text { Por ese motivo, interpone una demanda de impugnación de pater- } \\
\text { nidad solicitando se declare la inexistencia del vínculo paterno filial } \\
\text { entre el demandante y la niña y, accesoriamente, se excluya sus apelli- } \\
\text { dos de la partida de nacimiento y documento nacional de identidad. }\end{array}$ \\
$\begin{array}{l}\text { Marcela al contestar la demanda indica que el derecho a impugnar } \\
\text { la paternidad ha caducado. }\end{array}$ \\
\hline
\end{tabular}




\begin{tabular}{|c|c|}
\hline $\begin{array}{l}\text { Planteamiento del } \\
\text { caso }\end{array}$ & 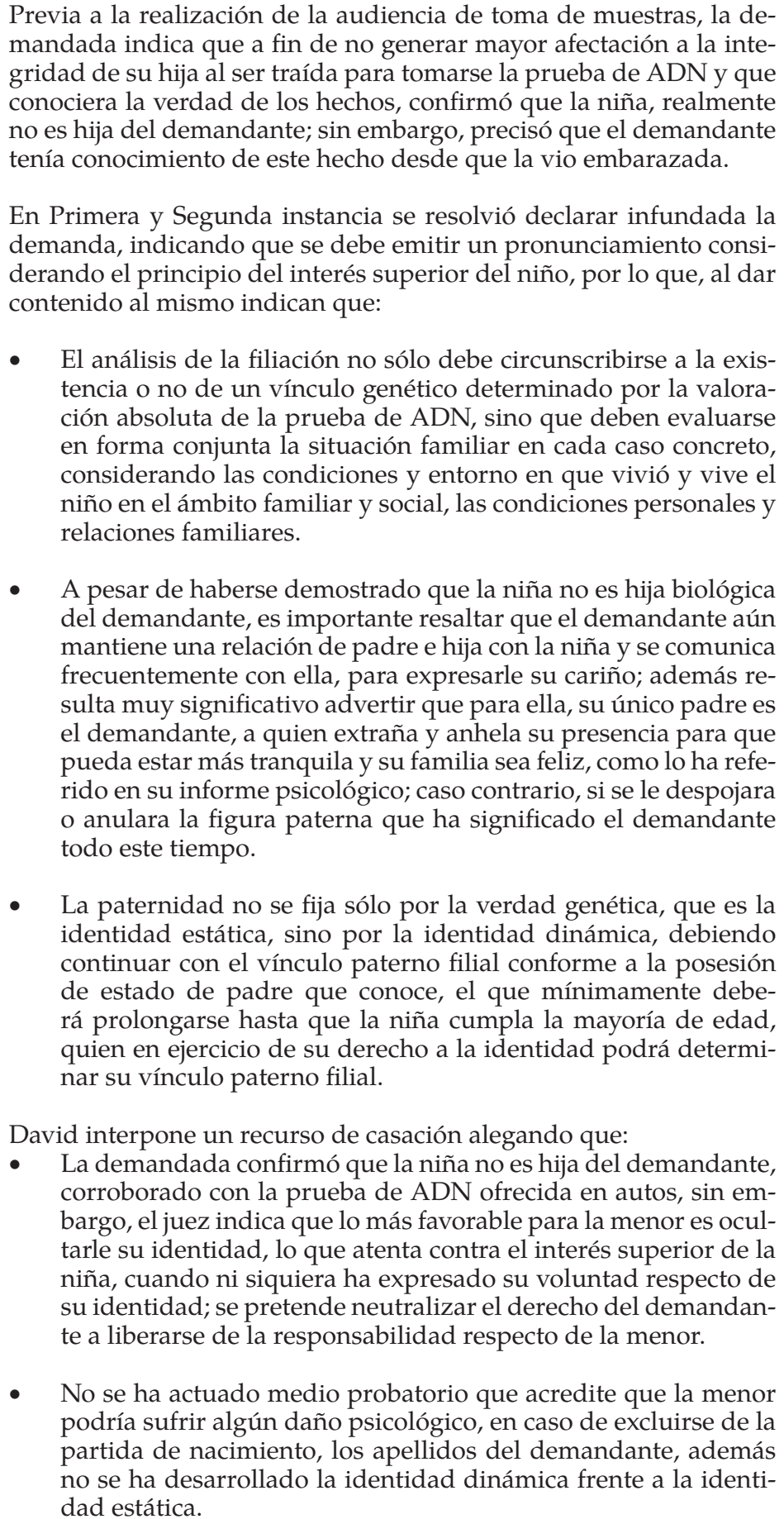 \\
\hline
\end{tabular}




\begin{tabular}{|c|c|}
\hline $\begin{array}{l}\text { Fundamentos de la } \\
\text { Corte Suprema }\end{array}$ & $\begin{array}{l}\text { La Sala Suprema respecto de la afectación al Principio de interés } \\
\text { superior del niño indica que la Convención del Niño dota a dicho } \\
\text { Principio de total efectividad, el cual busca el máximo bienestar del } \\
\text { niño y la plena efectivización de sus derechos, en su condición de } \\
\text { ser humano, principio que se tendrá en consideración al emitir pro- } \\
\text { nunciamiento. } \\
\text { Luego reseña las normas que desarrollan el derecho a la identidad } \\
\text { de las personas y señala que no se ha actuado un medio probatorio } \\
\text { científico relevante, teniendo en cuenta el interés superior del niño } \\
\text { y su derecho a la identidad, concluye que no se ha realizado una } \\
\text { debida valoración de los medios probatorios. } \\
\text { Resolviendo anular la sentencia emitida por la Sala Superior con la } \\
\text { finalidad que se cumpla con tomar la muestra de ADN. }\end{array}$ \\
\hline
\end{tabular}

Elaboración propia

En este caso, la persona que efectuó el reconocimiento de una niña - al llegar ella a los 9 años - presenta una demanda con la finalidad que se declare la inexistencia del vínculo paterno filial entre él y la niña y, accesoriamente, se excluya sus apellidos de la partida de nacimiento y documento nacional de identidad, alegando no ser el padre biológico. En dicho proceso, con la finalidad de evitar que a la niña se le tome la muestra de ADN, la madre reconoce que no es la hija biológica del demandante, lo que es corroborado con la prueba de $\mathrm{ADN}$, que previo al proceso, el demandante realizó.

Cabe resaltar que, en este proceso, la niña al ser entrevistada reconoció como su padre al demandante, respecto del cual, señala mantiene comunicación permanente y a quien extraña.

En la primera y segunda instancia se resuelve declarar infundada la demanda, precisando al resolver que este caso debe ser resuelto tomando en consideración el principio del interés superior del niño; por ello, priorizan la identidad dinámica de la menor, es decir, las condiciones en las que vive, su ambiente familiar, social y las relaciones establecidas, frente a la realidad biológica; concluyendo que, conforme a la evaluación psicológica, el despojar a la niña de la figura paterna que ella conoce le generaría un perjuicio, cumpliéndose así, con concretizar el concepto jurídico indeterminado.

Por el contrario, la Corte Suprema restringe su actuación al cuestionar, sobre la base de un enunciado principio de interés superior del niño, la falta de realización de la prueba genética, obligando que la niña sea sometida a la realización de dicho análisis, pese a que la madre, con la finalidad que su hija no sea más expuesta con este proceso, reconoce que el demandante no es el padre biológico. Ello, nos genera una interrogante ¿De qué manera someter a una niña, quien, a la fecha de expedición de la sentencia en la 
Corte Suprema, tenía 10 años, a una prueba genética resulta ser la medida más conveniente, si ella, ha constituido su identidad dinámica en atención al vínculo filial con el demandante?, ¿Puede obligarse a una niña a efectuarse la prueba genética?, la respuesta resulta evidente, no. Ello nos demuestra que, la máxima instancia del Poder Judicial no ha adoptado una decisión que resulte favorable para la niña que, a la fecha de realización de la prueba de ADN, ya tenía 14 años, prueba que tuvo que ser realizada por mandato judicial.

Difícilmente, esta nueva información podría alterar la resolución que fue emitida inicialmente por el Juez Especializado e inclinar la balanza a favor de un criterio que priorice la verdad biológica, estableciendo una medida que permita el desarrollo integral de una persona que quedaría sin filiación y sin el apellido que la ha identificado durante todo este tiempo; máxime si tomamos en consideración que, como lo ha establecido claramente Fernandez Sessarego, la identidad está conformada "no sólo los datos biológicos y otros de carácter generalmente estáticos, e invariables sino, además, aquellos que determinan la personalidad dinámica del sujeto" (1997, p. 249); razón por la cual, la adopción de una medida más favorable pasa por establecer no sólo los datos biológicos, sino también la personalidad y la historia personal creada a partir del entorno que la rodea, lo que significa saberse parte de una familia.

\section{Caso 4}

\begin{tabular}{|l|l|}
\hline Referencia & $\begin{array}{l}\text { Corte Suprema de Justicia de la República Sala de Derecho Consti- } \\
\text { tucional y Social Permanente Consulta Exp. 2372-2018 Lima }\end{array}$ \\
\hline Interrogante & $\begin{array}{l}\text { iSe delimitó el concepto del interés superior del niño en la aplicación } \\
\text { del control difuso? }\end{array}$ \\
\hline \multirow{2}{*}{$\begin{array}{c}\text { Planteamiento } \\
\text { del caso }\end{array}$} & $\begin{array}{l}\text { En agosto de 1998 nace una niña quien es reconocida en el año } 2004 \text { por } \\
\text { Roberto, es decir, cuando ella tenía } 6 \text { años } \\
\text { En el año 2010, Roberto toma conocimiento que la niña no es su hija } \\
\text { biológica y decide dejar de entregar el dinero para la manutención. La } \\
\text { demanda de alimentosion, en la que se le condena al padre a cumplir con } \\
\text { el pago de la pensión. }\end{array}$ \\
$\begin{array}{l}\text { En el año 2014, Roberto interpone una demanda de impugnación de } \\
\text { paternidad en contra de la madre y la hija (menor de edad). } \\
\text { Durante la tramitación del proceso se constató mediante la prueba de } \\
\text { ADN que Roberto no es el padre biológico de la niña. }\end{array}$ \\
\hline
\end{tabular}




\begin{tabular}{|c|c|}
\hline $\begin{array}{c}\text { Planteamiento } \\
\text { del caso }\end{array}$ & $\begin{array}{l}\text { En Primera se resolvió amparar la demanda interpuesta alegando que } \\
\text { el derecho de identidad debe priorizar por sobre una norma legal, } \\
\text { pues la demanda se interpuso excediendo el plazo de } 90 \text { días dispues- } \\
\text { tos en el Código Civil, siendo el medio idóneo para resolver la prueba } \\
\text { de ADN, ello en atención al interés superior del niño. } \\
\text { Este expediente al inaplicar una norma de carácter legal es elevado en } \\
\text { consulta a la Corte Suprema. }\end{array}$ \\
\hline $\begin{array}{l}\text { Fundamentos } \\
\text { de la Corte } \\
\text { Suprema }\end{array}$ & $\begin{array}{l}\text { La Sala Suprema aprueba la consulta indicando que: } \\
\text { (i) El derecho de identidad es un derecho fundamental que no } \\
\text { sólo comprende la identificación del menor, sino también los } \\
\text { aspectos de índole social, cultural, entre otros que permiten } \\
\text { definir la personalidad, el cual para su definición debe tener en } \\
\text { consideración el principio de interés superior del niño. } \\
\text { (ii) En atención a este principio, inaplica el artículo } 400 \text { del Código } \\
\text { Civil, el cual, establece un plazo de } 90 \text { días para impugnar la } \\
\text { paternidad extramatrimonial. }\end{array}$ \\
\hline
\end{tabular}

Elaboración propia

Esta última sentencia, refleja una posición asumida de manera constante al resolver las consultas, por la inaplicación de una norma de carácter legal por la colisión con una norma de carácter constitucional, priorizando el derecho a la identidad biológica frente a un plazo de caducidad conferido a quien pretende cuestionar la paternidad, interpretación que se indica se sustenta en la aplicación del principio del interés superior del niño.

En el presente caso, un padre quien reconoce a una niña 6 años después de su nacimiento; sin embargo, cuando la niña ya tiene 10 años se entera que no es su padre biológico y, espera 4 años más para impugnar la paternidad, presentando una demanda, la cual es amparada por las instancias del Poder Judicial, alegando el respeto al derecho de la identidad que debe tener la niña y en amparo del interés superior del niño.

Principio que sólo es mencionado para amparar la aplicación del control difuso, pero que en modo alguno es desarrollado, a fin de poder indicar de qué manera la decisión adoptada resulta la más favorable para la niña.

Tenemos una niña que a los 6 años es reconocida con el apellido que el padre le otorga, quien le confiere una manutención, en mérito a una sentencia que obliga al padre a cumplir con su obligación; sin embargo, al cumplir los 18 años (tomando en consideración la fecha de emisión de la primera instancia), pierde la filiación que hasta ese momento tenía y sin vínculo paterno alguno. 
Las preguntas que surgen en este caso son: ¿cómo esta decisión puede ser la más favorable?, ¿cuál es la ponderación que efectúa la Corte Suprema para, 4 años después de tomar conocimiento de la inexistencia de vínculo biológico, se desvincule a una persona del nexo parental?, ¿de esta forma se prioriza el derecho de identidad de una persona cuando a partir de la fecha desconoce su realidad paterna?, ¿cómo se desarrolla el principio del interés superior del niño?

El análisis de las sentencias emitidas por los órganos jurisdiccionales demuestra que ellos han restringido su actuación al reconocer la existencia de este principio jurídico sin darle contenido previo al resolver los casos concretos.

Consideramos que la delimitación del concepto indeterminado debe efectuarse, en cada caso, estableciendo una ponderación entre las medidas relevantes aplicables, sopesando entre ellas, cual es la que resulta más beneficiosa, considerando las opiniones de los niños o adolescentes involucrados justificando la decisión, de tal manera que se cumpla con los parámetros establecidos normativamente; para ello, puede recurrirse a la estructura que nos plantea Cassagne, evidenciando la zona de certeza positiva, la zona de incertidumbre y la zona de certeza negativa, de tal manera que las decisiones a adoptar sean aquellas que permitan el desarrollo integral del menor involucrado en un conflicto familiar.

\section{CONCLUSIONES}

1. El Principio del Interés Superior del niño es uno de los enunciados más importantes y de mayor consideración frente a la solución de conflictos familiares, cuyo carácter abstracto determina la necesidad de concretizar su contenido, en el caso concreto.

2. Normativamente, se han establecido parámetros que permiten su desarrollo, los cuales son de obligatorio cumplimiento para todas las instituciones vinculadas, quienes deben justificar la decisión adoptada frente a la colisión de dos derechos.

3. Las instancias judiciales al resolver los procesos identifican la existencia del principio; sin embargo, no determinan cual es el contenido asignado ni efectúan una adecuada ponderación que permitan demostrar que la decisión adoptada resulta la más beneficiosa.

4. La interpretación adecuada de este principio pasa por reconocer que el núcleo fijo está constituido por las medidas a adoptar las 
cuales deben permitir el desarrollo integral de los niños, la zona de incertidumbre, cuáles son los derechos en colisión y, la zona de certeza negativa estará determinada por la imposibilidad de poner en riesgo la salud emocional y física de los niños.

5. Una adecuada ponderación supone priorizar la opinión de los niños y niñas, considerando el grado de madurez y comprensión del caso, (i) brindando seguridad para la realización de visitas con supervisión, frente a las amenazas proferidas por el progenitor de llevarse al menor; (ii) evaluando los sentimientos que experimenta un niño o niña que es obligado a retornar a su país de origen sin la progenitora con la que ha convivido toda su vida y tener que retomar la relación con su presunto agresor; (iii) analizando de qué manera pueda afectar a una adolescente el conocer que el apellido paterno que usa y que el nombre de la persona que figura como padre en su partida de nacimiento, no tiene un vínculo biológico con ella.

6. Resulta, por tanto, indispensable que la decisión a adoptar priorice el otorgar al niño, niña o adolescente un entorno familiar que permita un crecimiento adecuado, libre de violencia, permitiendo el desarrollo de vínculos familiares, siempre que estos resulten favorables.

\section{REFERENCIAS}

Belloso, N. (2017). La concreción del interés (superior) del menor a partir de los conceptos jurídicos indeterminados: la iidoneidad? De la mediación familiar. Anuario de la Facultad de Derecho (Universidad de Alcalá), 1-42.

Cárdenas, E. (2011). El Interés Superior del Niño. Letras Jurídicas. Revista de los investigadores del Instituto de Investigaciones Jurídicas U. V. Universidad Veracruzana

Cassagne, J. C. (2009). La discrecionalidad administrativa. Foro Jurídico , 82-91.

Fernández Sessarego, C. (1997). Daño a la identidad personal. THEMIS Revista De Derecho, (36), 245-272. Recuperado a partir de https:// revistas.pucp.edu.pe/index.php/themis/article/view/11743

Ortega, I. (2002). El Interés Superior del Niño en las Situaciones de Crisis Familiar: Una Perspectiva Comparada en el Ámbito de la Unión Europea. Psicopatología Clínica, Legal y Forense. Vol. 2 N³, pp87-10 
Pacheco, M. (2013). Los conceptos jurídicos indeterminados: la mercadería. Controversias y soluciones. Quito: Corporación Editora Nacional.

Ratvellat, I. (2013). El Interés Superior del Niño: Concepto y Delimitación del Término. Educatio Siglo XXI. 30(2), pp. 89-108. https://revistas. um.es/educatio/article/view/153701

Torres, F. (2007). El Interés Superior del Niño en la Perspectiva del garantismo jurídico en México. Alegatos Universidad Autónoma de México. http:/ / alegatos.azc.uam.mx/index.php/ra/article/view/483

\section{Documentos Legales}

Congreso de la República. (17 de junio de 2016). Ley que establece parámetros y garantías procesales para la consideración primordial del interés superior del niño. [Ley N 30466]. DO: Diario Oficial El Peruano.

Decreto № 002-2018-MIMP de 2018. Por medio del cual se aprueba el Reglamento de la Ley № 30466, Ley que establece parámetros y garantías procesales para la consideración primordial del interés superior del niño. 30 de mayo de 2018. DO: Diario Oficial El Peruano.

ONU: Asamblea General, Convención sobre los Derechos del Niño, 20 noviembre 1989, United Nations, Treaty Series, vol. 1577, p. 3, https://www. refworld.org.es/docid/50ac92492.html [Accesado el 01 Julio 2021]

\section{Resoluciones Relevantes:}

Corte Suprema de Justicia de la República. Sala Civil Permanente. Casación No 516-2019 ICA; 03 de setiembre de 2020.

Corte Suprema de Justicia de la República. Sala Civil Permanente. N. 2728 2017 LIMA NORTE; 03 de setiembre de 2020.

Corte Suprema de Justicia de la República. Sala Civil Permanente. Casación № 5646-2017 CUSCO; 27 de setiembre de 2018.

Corte Suprema de Justicia de la República. Sala Constitucional y Social Permanente. Consulta Exp. 2372-2018 Lima; 21 de junio de 2019.

Fecha de aceptación : 20 de agosto de 2021

Fecha de recepción : 22 de noviembre de 2021 